\title{
The Efficacy of Structural Priming on the Acquisition of Double Object Construction by Chinese EFL Learners
}

\author{
Lin Jiang $^{1} \&$ Kang Huang ${ }^{1}$ \\ ${ }^{1}$ Faculty of English Language and Culture, Guangdong University of Foreign Studies, China \\ Correspondence: Lin Jiang, Faculty of English Language and Culture, Guangdong University of Foreign Studies, \\ Guangzhou, Guangdong, 510420, China. E-mail: jlin@gdufs.edu.cn
}

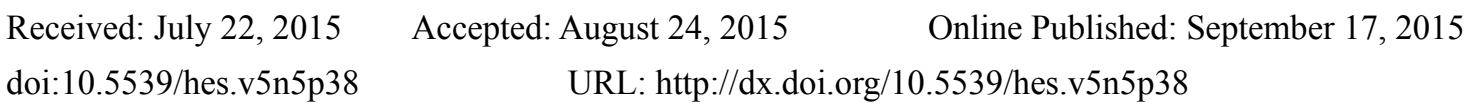

\begin{abstract}
Structural priming refers to the tendency of speakers to reuse the same structural pattern as one that was previously encountered (Bock, 1986). The effectiveness of structural priming has been an issue of much discussion in the field of second language acquisition over decades. This study aims at investigating the role of structural priming in Chinese English-as-a-foreign-language (EFL) learners' acquisition of double object (DO) construction. Specifically, it addresses two questions: (i) whether structural priming can facilitate second language acquisition of English DO construction in the short-term and long-term; (ii) whether different priming conditions by manipulating the intervening lags between prime and target have different learning effect. With a pretest-treatment-posttest-delayed posttest research design, 60 intermediate level Chinese EFL learners from three intact English classrooms in a junior college were assigned to three groups: control group, no-lag priming group and long-lag priming group. Results showed that the two treatment groups showed an overall increase in DO production in picture description tasks after the structural priming treatment, whereas the control group remained almost the same in target structure production over the three testing sessions. In addition, the no-lag priming group outperformed the long-lag priming group in the immediate posttest. These findings suggested that structural priming facilitated Chinese EFL learners' acquisition of DO construction both in the short-term and long-term. Moreover, manipulating the lags between prime and target can only mediate the short-term learning effect. These results are analyzed in light of frequency effect and contextual effect in the frame of usage-based theory of language acquisition.
\end{abstract}

Keywords: structural priming, double-object construction, frequency, context, usage-based theory

\section{Introduction}

In a classic study, Bock (1986) found strong tendencies of speakers to repeat syntactic structures that have recently been produced or comprehended. This effect is called structural priming (or syntactic priming). Structural priming appears to be quite general, in that it occurs in different languages, different structures, and among different people, whereas the effect cannot be explained in terms of lexical, semantic, or prosodic repetition (Bock, 1989; Bock \& Loebell, 1990).

In the past thirty years structural priming has received heavy scrutiny. It was first investigated among native language speakers as an underlying mechanism in language comprehension, production and processing (e.g., Bock, 1986). Another line of research in first-language (L1) literature was to explain structural priming effects (e.g., Bock \& Griffin, 2000; Chang, Dell, \& Bock, 2006; Chang, Dell, Bock, \& Griffin, 2000; Pickering \& Branigan, 1998). Three accounts have been put forward: a lexicalist residual activation account, an implicit learning account, and a multi-factorial account. Recently, structural priming studies have been extended to the second language acquisition (SLA) literature. One issue of concern is to examine whether bilingual syntactic processing is shared or separate by using structural priming across languages (e.g., Hartsuiker, Pickering, \& Veltkamp, 2004; Schoonbaert, Hartsuiker, \& Pickering, 2007). Additionally, a few SLA studies have explored whether structural priming in interactive contexts plays a role in second language (L2) development (e.g., McDonough, 2006; McDonough \& Mackey, 2008). However, conclusions that can be drawn from these L2 studies are quite limited as this line of research is not adequate; Moreover, the long-term effects of structural priming on L2 development were not fully uncovered. Thus, it was suggested that more fine-grained studies should be conducted to examine the long-term effects of structural priming on L2 development. 
In SLA literature, it was found that L2 English learners had difficulty in learning double object (DO) dative forms (e.g., The woman told her son a story), which was evidenced by their difficulties in producing them and thus do not frequently use them when compared with the syntactic alternation-prepositional-object (PO) dative forms (e.g., The woman told a story to her son) (e.g., Jiang, 2009; Shin 2008, 2010). This learning difficulty, according to Larson (1988), might be due to the different lexical content and different case-assignment schemes of DO construction. On the basis of the fact that learners in structural priming can produce the primed sentence and generalize the same structure to new utterances, Bock and Grifin (2000) suggested that structural priming involved learning processes themselves within a system that was organized for learning how to produce sequences of words to express message. Therefore, if DO structure is primed and priming effects have accumulated through the priming session, then participants are more likely to produce DO datives instead of the alternate PO structure in the subsequent production, it might be argued that structural priming benefits L2 learning of DO construction. The present study attempts to address this issue by investigating the following two research questions.

(a) Whether structural priming can facilitate Chinese EFL learners' acquisition of DO construction in the short-term and long-term?

(b) Whether different priming conditions by manipulating the intervening lags between prime and target have different learning effect?

\section{Literature Review}

\subsection{The Mechanism of Structural Priming}

Structural priming refers to a speaker's tendency to reuse the same structural pattern as one that was previously encountered (Bock, 1986). For example, when a speaker hears or produces a DO dative like The boy gave the girl a cat, he or she tends to use the same structure to describe a transfer event in a subsequent utterance such as The woman told her son a story, instead of the alternate PO dative The woman told a story to her son. The occurrence of structural priming has been observed even when the initial and subsequent utterances have different content words, closed-class elements, and thematic compositions and share no topical or pragmatic similarities (e.g., Bencini \& Goldberg, 2000; Bock, 1986, 1989; Bock \& Loebell, 1990). To explain structural priming effects, there have been three accounts: a lexicalist residual activation account (Pickering \& Branigan, 1998), an implicit-learning account (Bock \& Griffin, 2000; Chang, Dell \& Bock, 2006; Chang, Dell, Bock, \& Griffin, 2000), and a multi-factorial account (Ferreira \& Bock, 2006; Hartsuiker, Bernolet, Schoonbaert, Speybroeck, \& Vanderelst, 2008). We explain each of these accounts in what follows.

\subsubsection{The Lexicalist Residual Activation Account}

The lexicalist residual activation account holds that structural priming is the result of residual activation of a prime that immediately precedes the target in explicit memory. According to Pickering and Branigan (1998), a lemma node (e.g., give) was linked to nodes specifying category information (e.g., verb), feature information (e.g., singular, present tense), and combinatorial information (specifying the argument structures). A [V NP NP] combinatorial node is activated when give is used in a DO dative sentence with two post-verbal noun phrases (e.g., give the girl a cat) and that a [V NP PP] combinatorial node is activated when it is used in a PO dative sentence with a noun phrase and a prepositional phrase (e.g., give a cat to the girl). Processing a prime sentence activates a lemma node and its combinatorial node with the link between the nodes more active. The combinatorial node's residual activation in explicit memory leads to an increased probability that the same syntactic structure will be selected in the subsequent production. For instance, when the sentence The boy gave the girl a cat is spoken or heard, the lemma of give and its combinatorial node [V NP NP] are activated. The residual activation increases the probability of production of the sentence The woman told her son a story in a subsequent utterance that shares the same combinatorial node, instead of the alternate structure The woman told a story to her son.

According to this account, explicit memory of the prime sentence's surface structure can cause structural repetition (Bock \& Griffin, 2000; Chang et al., 2006; Hartsuiker et al., 2008). Prime sentences serve as a retrieval cue, so that speakers are likely to recall from memory and reuse the prime sentence's structure. Bock, Loebell, and Morey (1992) found that providing instruction to participants influenced structural priming; greater structural priming was observed among participants instructed to remember syntax than among participants instructed to remember meaning. This result, according to Ferreira and Bock (2006), "suggests that structural priming is sensitive to explicit memory for syntax, which in turn is consistent with the possibility that structural priming might be due to explicit-memory functioning" (p. 1020). 
In particular, the lexicalist residual activation account explains the so-called lexical boost effect observed in short-term priming, which means that word repetition can promote structural priming. Pickering and Branigan (1998) first discovered that verb repetition between prime and target could improve structural priming. Gries and Wulff (2005) counted 3003 pairs of DO and PO sentences, and found that structural priming happened in two-thirds of the pairs, and the occurrence of the structural priming increased, when an identical verb was used in both prime and target. Cleland and Pickering (2003) found that the repetition of nouns in complex noun phrases could also promote structural priming. Moreover, Branigan, Pickering, and Cleland (2000) found enhanced priming with verb repetition when participants heard rather than produced the target structure, indicating that merely comprehending an utterance is enough to enhance structural priming. However, the function words showed no lexical boost effect. For example, the preposition's (i.e., to or for) repetition in the PO datives could not enhance priming effect (Bock, 1989). Besides, no enhanced priming was found when the form of the verb was repeated compared with a verb differing in tense, aspect, or number. This is predicted because the activated link is between lemma node with combinatorial node rather than with featural node.

\subsubsection{The Implicit Learning Account}

The implicit learning account indicates that structural priming is a process of strengthening the syntactic representation link. When producing or comprehending an utterance, people have to know how to map the meaning to the functions (which is the subject, and which is the object), and how to map the functions to the component sequence, and the structural priming can reinforce the mapping. There are three main features illustrating the point that structural priming is implicit. First, studies in this camp showed long-lasting structural priming effect. In particular, Bock and Griffin (2000) examined the persistence of structural priming when the prime sentence was immediately followed by the target picture and when there were one, two, four, or ten intervening filler sentences between prime and target. It was found that structural priming was as robust when ten fillers intervened between prime and target as it was when no fillers intervened. They argued that their results could not be explained by the short-term residual activation account. Instead, the results constituted evidence for an implicit learning account in which "there is longer-term adaptation in the cognitive learning mechanisms for sentence creation" (Shin \& Christianson, 2012, p. 935). Second, structural priming does not depend on explicit memory (Bock, Loebell, \& Morey, 1992). For example, the anterograde amnesia patients whose explicit memory has been injured seriously can show structural priming effect (Ferreira, Bock, Wilson, \& Cohen, 2005). In addition, Bock and Griffin (2000) showed that participants produced the primed sentence and generalized the same structure to new utterances without any explicit attention to the form of the priming sentences. Third, structural priming has an inverse-preference effect, which means that the low-frequency sentences can make greater priming effect (Hartsuiker \& Kolk, 1998). This effect fits in with the error-based implicit learning calculations,

\subsubsection{The Multi-Factorial Account}

Recently, a multi-factorial account has been proposed, which holds that both residual activation in explicit memory and implicit-learning process may contribute to structural priming (Ferreira \& Bock, 2006; Hartsuiker et al., 2008). Hartsuiker et al. (2008) designed four experiments to examine priming effects. Experiment 1 and 2 showed a lexical boost effect. Experiment 3 and 4 varied the number of filler sentences between prime and target and the results showed that structural priming persisted while the lexical boost decayed. The study supported a multi-factorial account of structural priming in which implicit learning rather than explicit memory was responsible for structural priming in long-lag conditions; in no-lag or short-lag conditions, structural priming might involve both, relying on explicit memory alone for lexical repetition. The present study follows the multi-factorial account to discuss the findings.

\subsection{Structural Priming in the L2 Literature}

Interaction researchers are the first to examine the relationship between structural priming and L2 learning. McDonough (2006) investigated whether structural priming in interaction activities could facilitate L2 development by using a confederate scripting technique. In the experiment, a participant carried out a picture description and matching activity with an interlocutor who was a confederate of the researcher. The participant and the confederate took turns (beginning with the confederate) describing a set of pictures to each other, using the verbs that were written under each picture. While listening to their partner's descriptions, the interlocutor searched for matching pictures from a group of related pictures displayed on the table in front of them (a barrier prevents them from seeing their partner's cards). Results showed that participants produced more PO datives when they had previously heard the PO structure than when they had not, which constitutes evidence of the beneficial effect of structural priming on production of the PO structure. McDonough suggested that further 
studies should investigate the function of structural priming in contexts where an interlanguage system provides an L2 speaker with a choice between structures that have a developmentally advanced form and a less advanced form to better examine L2 development after priming training.

As a follow-up study, McDonough and Mackey (2008) examined whether structural priming promotes the development of L2 English question forms, using a pretest-treatment-posttest design. In the study, 46 intermediate level Thailand learners of English carried out communicative activities with a more advanced L2 English interlocutor who had been scripted with developmentally advanced question forms. Results revealed that participants evidencing structural priming were more likely to advance to a higher stage in English question developmental sequence, indicating that structural priming plays a beneficial role in English question formation.

Unlike the above studies which focused on L2 learners' interaction with interlocutors and L2 development, Shin and Christianson's (2012) study tried to uncover L2 learners' internal cognitive processes in structural priming. It was the first to compare explicit instruction with implicit instruction in a structural priming paradigm. 48 Korean EFL learners were randomly and equally assigned to three different structural priming condition groups (no-lag, long-lag, and explicitly reinforced group, respectively). The target structures were complex DO datives and simple, separated phrasal-verb structures. Participants' language development was measured by the picture description task and the grammaticality judgment test. Results showed that explicit instruction combined with structural priming was more beneficial to short-term improvement than implicit instruction involving implicit learning alone in the form of long-lag structural priming. However, only implicit learning through long-lag structural priming can resulted in long-term improvement of the complex DO structure. Since the delayed learning effect in the study was measured only one day after the immediate posttest, it might not demonstrate a full view of the long-term effects of structural priming. This issue will be addressed in the present study.

\subsection{English DO Construction in L1 and L2 Acquisition}

English DO construction expresses transfer of possession and involves three participants: one acting as the subject and the other two acting as the objects. The syntactic and semantic configurations of English DO construction are illustrated below.

$\begin{array}{lllll} & \text { John } & \text { gave } & \text { Mary } & \text { a book. } \\ \text { Syntactic patterns } & \mathrm{NP}_{0} & \mathrm{~V} & \mathrm{NP}_{1} & \mathrm{NP}_{2} \\ \text { Semantic roles } & \text { Agent } & \mathrm{V} & \text { Recipient } & \text { theme } \\ \text { Grammatical functions } & \text { Subject } & \mathrm{V} & \text { Object }_{1} & \text { Object }_{2}\end{array}$

Baker (1979) is most often credited with recognizing the learnability problem with English DO construction. The puzzle is as follows: Why is it that the DO datives in (1) and (3) are grammatical, whereas in (2) and (4) are ungrammatical? It is generally accepted that there is some restriction disallowing some verbs from being realized in the DO construction. The agreement among syntactic as well as lexical-semantic analyses is that some sort of "possession constraint" is at work (e.g., Aoun \& Li, 1989; Jackendoff, 1990; Pinker, 1989). That is, the first object of the DO dative must be a potential possessor of the second object.

(1) Tom showed Mary the picture.

(2) *Tom described Mary the picture.

(3) Tom found Mary the money.

(4) *Tom collected Mary the money.

In the L1 literature, it was found that English children did sometimes produce DO forms in naturalistic data which were considered illicit in the adult grammar, as you can see from the following examples (Gropen, Pinker, Hollander, Goldberg, \& Wilson,1989: 217). Experimental data reinforce this finding. Mazurkewich and White (1984) tested three groups of L1 English-speaking children, of 9, 12, and 15 years of age with a grammaticality judgment task. Results showed that these 9-, 12-, and 15-year-olds overgeneralized the DO form at rates of $46.7 \%, 33.3 \%$, and $11.1 \%$, respectively.

(5) *You finished me lots of rings.

(6) *Jay said me no.

In the SLA literature, DO construction also poses learning difficulty for EFL learners. Shin $(2008,2010)$ found that low-level L2 learners often had problems in syntactic processing when producing English DO datives. One case in point is the ordering problem such as *The coach read the rules the team, *The lawyer took his girlfriend to spaghetti, and $*$ The old man rented to his neighbors apartment. 
Inagaki (1997) investigated the issue of transfer in this domain by contrasting adult Chinese and Japanese learners of English. According to Huang (1994), Chinese is like English both for tell-type verbs (which alternate) and for whisper-type verbs (which do not), the latter appearing only as PO datives. Yet unlike English, which allows the alternation with throw-type but not push-type verbs, Chinese allows neither type to alternate; both occur only in the PO form. Adopting the Fundamental Difference Hypothesis which posits transfer from the L1 as a possible source of knowledge for adult L2 acquisition, Inagaki predicted that Chinese learners of English would (i) accept the DO form with tell-type verbs but reject it with whisper-type verbs, and (ii) be unable to distinguish between (licit) throw-type DO datives and (illicit) push-types DO datives. As for Japanese, Inagaki (1997) maintained that it has no dative alternation and does not allow push-type verbs to occur in the DO dative form. Thus, Japanese learners of English were hypothesized, under the Fundamental Difference Hypothesis, to (i) know that the DO dative is illicit with push-types verbs but licit with throw-type verbs, and (ii) be unable to distinguish between (licit) tell-type DO datives and (illicit) whisper-types DO datives. Interestingly, unambiguous support for L1 transfer was found from the results of the 32 adult Chinese. However, the L1 Japanese speakers - contrary to both of Inagaki's predictions - did distinguish between tell- and whisper-type verbs but not push- and throw-type verbs. Inagaki (1997) conceded that the Japanese group's results contradict the transfer assumption of the Fundamental Difference Hypothesis. He concluded that L2 adults must rely purely on frequency in the input to learn these verbs one by one, speculating that these Japanese subjects have not been exposed to a high enough incidence of push-and throw-type verbs to be able to make the distinction.

In essence, current studies on L2 acquisition of English DO structures have laid too much emphasis on showing and analyzing L2 learners' different errors but rather less on how to draw on some learning enhancing variables. As described earlier in this section, structural priming methods are useful in doing research on L2 learning. Therefore, the present research exploits whether structural priming can promote L2 acquisition of English DO datives. In addition, the effects of different priming conditions will be tested.

\section{The Study}

\subsection{Participants}

Sixty Chinese EFL learners from three intact $1^{\text {st }}$-year English classrooms in a junior college in China participated in the experiment. All participants have learned English for at least 6 years and none of them had the experience of living in English-speaking countries. In the college, they received a three-hour form-focused English instruction every week. An English proficiency test, namely the Oxford Quick Placement Test (UCLES, 2001), was administered to all participants. A one-way ANOVA showed that there were no significant differences among the three groups in terms of their scores $(F(2,57)=.145, p>.05)$, and they were assessed as the lower-intermediate level. The three intact classes were randomly assigned as the long-lag priming group $(\mathrm{n}=20)$, the no-lag priming group $(n=20)$, and the control group $(n=20)$, with each group consisting of 6 females and 14 males.

\subsection{Target Structure}

In the present study, English DO structure was chosen as the target structure for three reasons. First, it is one of the most frequently used structures in structural priming studies and its priming effect has been confirmed in L2 production, which is a prerequisite condition for the present study. Second, DO construction poses learning difficulty for EFL learners (e.g., Shin, 2008, 2010), so it is insightful to exploit whether structural priming can facilitate its development. Third, compared with PO datives, DO datives can exhibit greater structural priming. A number of studies have observed that structural priming exhibited an inverse-preference pattern (Bock, 1986; Bock \& Griffin, 2000; Hartsuiker \& Kolk, 1998; Scheepers, 2003), which suggests that structures that are less preferred or less common exhibit greater structural priming, whereas structures that are more preferred or more common exhibit less structural priming. Since Chinese EFL learners often have difficulties in producing DO datives and thus do not frequently use them (Jiang, 2009), DO datives may exhibit greater priming and yield better learning effect than PO datives.

\subsection{Design}

This study employed a pretest-treatment-immediate posttest-delayed posttest research design. In the pretest, a picture description task was used to assess participants' initial knowledge of DO construction. The treatment session involved two priming conditions, namely no-lag priming and long-lag priming. An immediate picture description posttest measured short-term effects of structural priming and a delayed picture description posttest one week later measured long-term effects of structural priming. The control group participated in the three testing sessions but not the treatment session. 


\subsection{Procedure}

The experiment was individually carried out in front of a PC. On the first day of the experiment, all participants performed a picture description task (the pretest) for 10 minutes. They were instructed before the test that they were to describe pictures using words presented below the pictures with a simple sentence as quickly as possible. In the following treatment session, the two experimental groups were informed that they were going to see pictures and listen to spoken sentences describing the pictures, and they were asked to repeat what they had heard when they saw a picture with a red frame (i.e. prime pictures). They were also told that they would sometimes see pictures with red frames without spoken sentences (i.e., target pictures) and were asked to describe the pictures using the given verbs. The treatment session was self-paced and lasted approximately 35-45 minutes, varying slightly by individual. The control group did not get any treatment. After the treatment, all participants performed a picture description task (the immediate posttest) for 10 minutes. A week later, they performed another picture description task (the delayed posttest) for 10 minutes.

\subsection{Materials}

The materials for this study included pictures and spoken sentences. The pictures consisted of filler pictures, prime pictures and target pictures (see Figure 1). Filler pictures were used to elicit simple transitive sentences (e.g., The woman is writing a letter). Prime pictures and target pictures were used to elicit dative sentences (e.g., The woman is tossing the girls flowers). Sentences describing filler and prime pictures were orally recorded by a native speaker of English, and were presented along with their paired picture in an E-prime program. There is a verb below each picture. Spoken sentences describing pictures contain the given verbs and participants were required to use the given verbs to describe target pictures.

Pictures and spoken sentences were divided into testing materials and treatment materials. Testing materials consisted of three sets of target pictures, one for each testing session (i.e., pretest, immediate posttest, and delayed posttest). Each set had eight target pictures. Treatment materials consisted of filler and prime pictures with their paired spoken description sentences and target pictures. All materials were presented via E-prime 2.0 software.

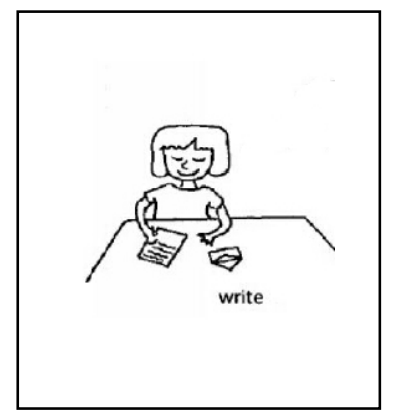

Filler Picture

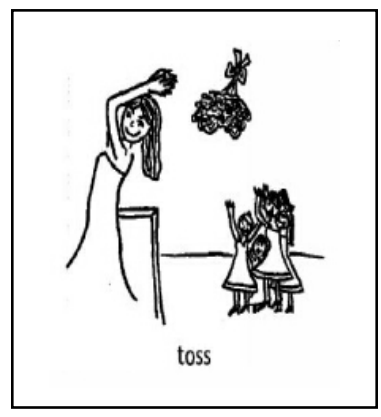

Prime Picture

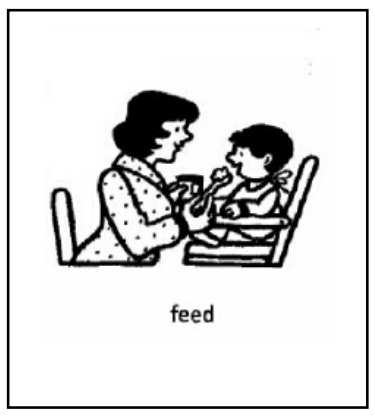

Target Picture

Figure 1. Examples of experimental pictures

\subsection{Treatment}

A sentence repetition and picture description task was employed in the structural priming treatment. Listening and repeating sentences served as prime, and describing target pictures served as target. Two priming conditions (i.e., no-lag priming and long-lag priming) were involved in this study. In no-lag priming condition, the target immediately followed the prime without fillers in between. The priming procedure contained eight trials in total. In each trial, four filler pictures along with their paired spoken description sentences were first presented, which were followed by two prime pictures along with their paired spoken description sentences. When the second prime picture appeared again with a red frame, participants were required to repeat the spoken sentence. Then a target picture with a red frame was presented and participants needed to describe that picture with the given verb.

The long-lag priming condition shared the same set of treatment materials as the no-lag priming condition with the order of presentation changed only; that is, four fillers intervened between prime and target. The priming procedure also contained eight trials in total. In each trial, two prime pictures along with their paired spoken description sentences were first presented. When the second prime picture appeared again with a red frame, participants were required to repeat the spoken sentence. Then four filler pictures along with their paired spoken 
description sentences were presented, which was followed by a target picture with a red frame and participants needed to describe that picture with the given verb.

\subsection{Scoring}

All verbal responses in the three testing sessions were recorded and transcribed for coding. The picture description was scored as target (DO dative), alternate (PO dative), and other (other structures or incomplete sentences). Errors related to articles, tense and agreement in participants' production were ignored. Coding was carried out by two Chinese learners of English who were postgraduate students majored in applied linguistics. Interrater reliability calculated by the Pearson correlation was $94 \%$, and the remaining $6 \%$ were resolved after discussion.

To be scored as target, the ditransitive verb should be immediately followed by a noun phrase which acted as the recipient and then a noun phrase which acted as the theme. To be scored as alternate, the ditransitive verb should be immediately followed by a noun phrase which acted as the theme and then a prepositional phrase with to or for, which acted as the recipient.

\section{Results}

The descriptive statistics for production proportions are reported in Table 1. The overall patterns of the target production across the testing sessions are illustrated in Figure 2. It can be seen that the control group's production of DO datives remained almost the same over the three sessions. However, the target production of both treatment groups increased dramatically in the immediate and delayed posttests after the treatment, though there was a decrease from the immediate posttest to the delayed posttest. The repeated measures ANCOVA results, as reported in Table 2, showed significant differences in sessions, $F=29.08, p<.001$, and in conditions, $F=14.5, p<.001$. Additionally, a significant interaction between sessions and conditions was found, $F=10.774$, $p<.001$. The results of each testing session are reported below.

Table 1. Response proportions (\%) in the picture description task

\begin{tabular}{ccccccc}
\hline \multirow{2}{*}{ Condition } & \multicolumn{2}{c}{ Pretest } & \multicolumn{2}{c}{ Immediate Posttest } & \multicolumn{2}{c}{ Delayed Posttest } \\
& Target & Alternate & Target & Alternate & Target & Alternate \\
\hline No-lag priming & 13.75 & 60.63 & 63.13 & 15.63 & 35.00 & 46.88 \\
Long-lag priming & 11.25 & 56.25 & 35.00 & 41.88 & 29.38 & 53.75 \\
Control & 11.25 & 50.00 & 10.00 & 41.88 & 10.63 & 41.88 \\
\hline
\end{tabular}

Table 2. Effect of session and condition on production of the target structure

\begin{tabular}{cccccc}
\hline Source & SS & df & MS & F & P \\
\hline Session & 1.745 & 2 & .872 & 29.080 & $<.001$ \\
Condition & 2.151 & 2 & 1.075 & 14.500 & $<.001$ \\
Session*Condition & 1.293 & 4 & .323 & 10.774 & $<.001$ \\
\hline
\end{tabular}

Note. SS=Sum of Squares; $\mathrm{df}=$ degree of freedom; MS=Mean Square

In the pretest, a one-way ANOVA showed that there was no significant difference among the three groups in production of the target structure, $F(2,57)=.240, p>.05$, indicating that participants in the three groups had an equivalent knowledge of the target structure before the priming treatment, so the baseline was equivalent across the groups.

In the immediate posttest, a one-way ANOVA with posthoc tests showed that there were significant differences among the three groups, $F(2,57)=34.976, p<.05$. Specifically, both the no-lag priming group $(p<.001)$ and the long-lag priming group $(p<.001)$ produced significantly more target structures than the control group, and the no-lag priming group also outperformed the long-lag priming group $(p<.001)$. These findings suggest that structural priming can facilitate Chinese EFL learners' acquisition of DO datives, and the no-lag priming was superior to the long-lag priming on short-term improvement of DO datives.

In the delayed posttest, a one-way ANOVA with posthoc tests showed that there were significant differences 
among the three groups, $F(2,57)=3.992, p<.05$. Specifically, both the no-lag priming group $(p<.05)$ and the long-lag priming group $(p<.05)$ produced significantly more target structures than the control group, and there was no significant difference between the two treatment groups. These findings indicate that the two priming conditions had similar beneficial effect on long-term improvement of DO datives.

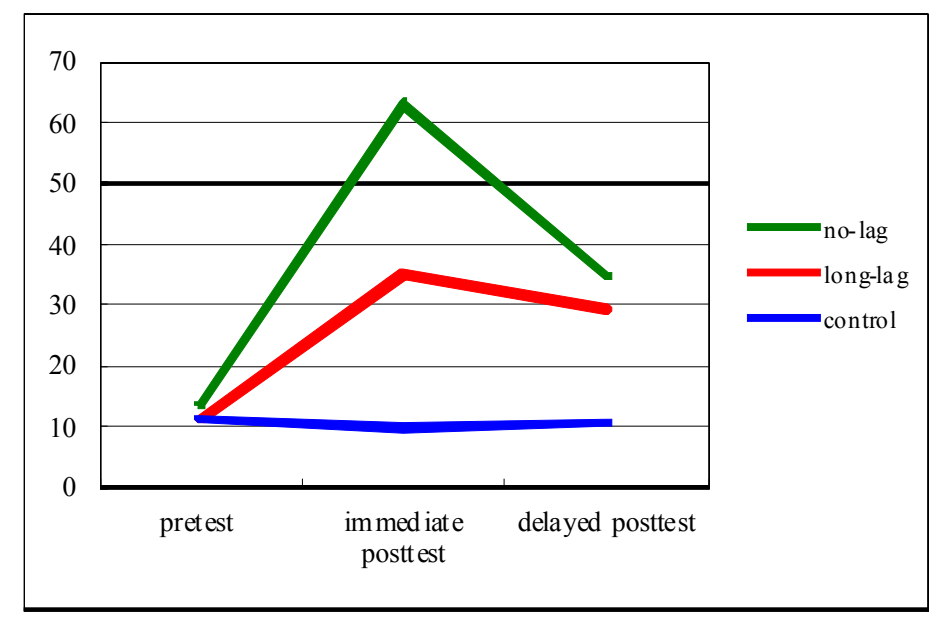

Figure 2. Production of the target structure across sessions

\section{Discussion}

\subsection{Effects of Structural Priming on L2 Acquisition of English DO Construction}

In the present study, after comprehending and producing DO dative sentences in the priming treatment, the two treatment groups produced more target sentences than the control group did in the two posttests. The results showed that structural priming can facilitate Chinese EFL learners' acquisition of DO construction both in the short-term and long-term. According to usage-based theory of language acquisition, knowledge of a language is based on knowledge of actual usage and generalizations made over usage events (Goldberg, 2006; Langacker, 1987, 1991; Tomasello, 2003). The typical route of emergence of constructions is from formula, through low-scope pattern, to construction. Frequency of use has a determinant impact on the emergence of linguistic structures (Ellis, 2002), and it can be further divided into token frequency and type frequency. Token frequency is how often a specific word or a phrase appears in the input. Type frequency refers to how many different lexical items can be applied to a certain pattern, paradigm, or construction. High token frequency promotes the entrenchment or conservation of irregular forms and idioms. High type frequency leads to the productivity of syntactic pattern, because the more lexical items that are heard in a certain position in a construction, the less likely that it is the construction associated with a particular lexical item and the more likely a general category is formed over the items that occur in that position and therefore make it more accessible for further use with new items (Bybee \& Thompson, 2000).

Priming treatment in the present study enabled learners to use the same dative verbs for many times, and more importantly to use many different dative verbs in the picture description task. Increased token frequency promoted the entrenchment of DO constructions, while increased type frequency strengthened the generality and abstraction of DO construction. Altogether, frequent use of DO constructions in the priming has an immediate impact on the representation and activation of linguistic knowledge. Every time a participant uses a DO dative, it reinforces its mental representation, which in turn facilitates the activation of this expression in language use (Diessel, 2004).

This finding got its support from a study by McDonough (2006). In the study, when participants were exposed to PO and DO primes equally, they produced $63 \%$ of the DO targets with only two verbs ask and teach and did not produce a DO sentence for eight other dative verbs (bring, cook, cut, knit, make, pass, pour, and toss). However, when participants were exposed to DO primes exclusively, they produced $49 \%$ of the total DO targets with the verb ask and teach and produced at least one DO sentence for eight other dative verbs. McDonough argued that the repeated exposure to a construction in the priming task might have helped these L2 speakers recognize that the DO dative form is a general category rather than a lexically specific construction. She concluded in the study 
that when L2 speakers used a syntactic form as a formula or as a limited-scope pattern, structural priming might lead them to produce that form with new lexical items, which could facilitate the acquisition of more abstract representations.

Apart from frequency effect, contextual factors involved in structural priming also promoted the acquisition of DO construction. According to Wang's (2009) "Learn Together, Use Together" principle, if L2 linguistic forms are acquired in rich contexts, they can be elicited more easily in similar contexts, and learners are more likely to use these linguistic forms in their future production. Sentence repetition and picture description task adopted in the present study provided rich context for the use of DO construction. All prime and target pictures in the experiment showed events involving three objects: an agent of an action (e.g., the woman), a theme undergoing the action (e.g., flowers), and a recipient of the action (e.g., the girls). The repeated presentation of these pictures along with their spoken description sentences helped learners get familiar with the context in which DO construction is used. Similar contexts in the posttests activated their use of DO datives, yielding learning outcomes.

It should be noted that although the two treatment groups produced significantly more DO constructions than they did in the pretest, there was a sharp decrease from the immediate posttest to the delayed posttest, indicating that the learning effect of structural priming diminished as time went by. According to the multi-factorial account, the underlying mechanisms of structural priming involve both residual activation and implicit learning. Shortly after the priming treatment, the two mechanisms functioned cooperatively and effectively in the immediate posttest and thus led to a large amount of DO construction production. However, in the delayed posttest, residual activation effect decayed and implicit learning was constrained, and thus the amount of DO construction production decreased. Implicit learning of L2 grammatical construction is constrained by many factors like the amount of input and depth of processing. Gai and Wen (2013) investigated whether Chinese EFL learners can acquire grammatical rules implicitly. It was found that implicit learning could happen but the amount of input could heavily affect the learning efficacy. In the case of the present study, structural priming treatment provided learners with input of DO construction and opportunities for deep processing. However, only one treatment session cannot guarantee the learning efficacy to persist for a long time. Since the delayed posttest was administered a week after the treatment, it is highly probable that the learning results decayed without enough input, processing and timely consolidation during the one-week interval. Therefore, it was not surprising to find that $\mathrm{DO}$ dative production diminished from the immediate posttest to the delayed posttest.

\subsection{Effects of Different Priming Conditions on L2 Acquisition of English DO Constructions}

In the present study, priming conditions were operationalized by manipulating the fillers between prime and target. Results showed that in the immediate posttest, the no-lag priming group produced significantly more DO datives than the long-lag priming group, whereas in the delayed posttest, the two groups showed no significant difference in target production. Actually, whether participants would use the structure of the prime sentence in their subsequent production depended on the processing load needed for retrieving the syntactic information retained in their memory. When no fillers intervened, the syntactic information (DO structure) of the prime sentence was better retained in participants' memory. Participants needed less processing load to recall the structure in the short-term memory, so they were more likely to produce DO datives in the immediate picture description task, resulting in greater learning effect. However, when four fillers intervened, what retained in participants' memory was the syntactic information of the intervening sentence other than that of the prime sentence. Since participants had more processing load to retrieve DO construction information in their memory, they tended to use other structures than DO construction in the immediate picture description task, resulting in less learning effect. The above analysis explained why the no-lag priming group produced significantly more DO datives than the long-lag priming group in the immediate posttest.

As time went by, the priming effect for both treatment groups had decayed. Therefore, it might be equally difficult for them to retrieve the syntactic information of the prime sentence in the delayed picture description task. As a consequence, both groups produced similar amount of DO dative sentences in the delayed posttest, which was significantly less than what they did in the immediate posttest.

\section{Conclusion}

Structural priming is a hot issue in psycholinguistics and SLA research. Most previous studies dealt with the occurrence and mechanisms of structural priming. The present study took the research a step further by exploring the beneficial effect of structural priming on L2 acquisition of English DO datives. By employing a pretest-treatment-posttest-delayed posttest research design, the present study showed that structural priming can facilitate Chinese EFL learners' acquisition of DO construction in the short-term and long-term, and that 
manipulating the fillers between prime and target can mediate short-term learning effect rather than long-term learning effect. These findings suggested that structural priming involved both residual activation in explicit memory and implicit-learning process. The frequent use of target structure in the priming has an immediate impact on the representation and activation of linguistic knowledge. Every time a participant uses a DO dative, it reinforces its mental representation, which in turn facilitates the activation of this expression in language use (Diessel, 2004). Although the present study indicated that structural priming can facilitate L2 learning, it should be born in mind that these findings can only be limited to the DO construction and the lower- intermediate level Chinese EFL learners. Future research targeting at other linguistic structures and different level of learner population are called for to provide more evidence.

\section{Acknowledgement}

This research was supported by a grant from the China National Social Science Foundation (14CYY018).

\section{References}

Aoun, J., \& Li, Y. (1989). Scope and constituency. Linguistic Inquiry, 20, 141-172.

Baker, C. L. (1979). Syntactic theory and the projection problem. Linguistic Inquiry, 10, 533-581.

Bencini, G. M., \& Goldberg, A. E. (2000). The contribution of argument structure constructions to sentence meaning. Journal of Memory and Language, 43, 640-651.

Bock, J. K. (1986). Syntactic persistence in language production. Cognitive Psychology, 18, 355-387. http://dx.doi.org/10.1016/0010-0285(86)90004-6

Bock, J. K. (1989). Closed-class immanence in sentence production. Cognition, 31, 163-186. http://dx.doi.org/10.1016/0010-0277(89)90022-X

Bock, J. K., \& Griffin, Z. M. (2000). The persistence of structural priming: Transient activation or implicit learning? Journal of Experimental Psychology: General, 129, 177-192. http://dx.doi.org/10.1037/0096-3445.129.2.177

Bock, J. K., \& Loebell, H. (1990). Framing sentences. Cognition, 35, 1-39. http://dx.doi.org/10.1016/0010-0277(90)90035-I

Bock, K., Loebell, H., \& Morey, R. (1992). From conceptual roles to structural relation: Bridging the syntactic cleft. Psychological Review, 99, 150-171. http://dx.doi.org/10.1037/0033-295X.99.1.150

Branigan, H. P., Pickering, M. J., \& Cleland, A. A. (2000). Syntactic co-ordination in dialogue. Cognition, 75, B13-B25. http://dx.doi.org/10.1016/S0010-0277(99)00081-5

Bybee, J. L., \& Thompson, S. (2000). Three frequency effects in syntax. Berkley Linguistic Society, 2, 65-85. http://dx.doi.org/10.3765/bls.v23i1.1293

Chang, F., Dell, G. S., \& Bock, J. K. (2006). Becoming syntactic. Psychological Review, 113, 234-272. http://dx.doi.org/10.1037/0033-295X.113.2.234

Chang, F., Dell, G. S., Bock, J. K., \& Griffin, Z. M. (2000). Structural priming as implicit learning: A comparison of models of sentence production. Journal of Psycholinguistic Research, 29, 217-229.

Cleland, A. A., \& Pickering, M. J. (2003). The use of lexical and syntactic information in language production: Evidence from the priming of noun-phrase structure. Journal of Memory and Language, 49, 214-230. http://dx.doi.org/10.1016/S0749-596X(03)00060-3

Diessel, H. (2004). The acquisition of complex sentences. Cambridge: Cambridge University Press.

Ellis, N. (2002). Frequency effects in language processing: A review with implications for theories of implicit and explicit language acquisition. Studies in Second Language Acquisition, 24, 143-188. http://dx.doi.org/10.1017/S0272263102002024

Ferreira, V. S., \& Bock, J. K. (2006). The functions of structural priming. Language and Cognitive Processes, 21, 1011-1029. http://dx.doi.org/10.1080/01690960600824609

Ferreira, V. S., Bock, J. K., Wilson, M., \& Cohen, N. J. (2005). Structural persistence in anterograde amnesia: Evidence for implicit learning. Paper presented at the 46th Annual Meeting of the Psychonomic Society, Toronto, 11-13 October 2005.

Gai, S.-H., \& Wen, Q.-F. (2013). Learning without awareness by Chinese EFL learner. Foreign Language Teaching and Research, 45, 557-567. 
Goldberg, A. E. (2006). Constructions at work: The nature of generalization in language. Oxford: Oxford University Press.

Gries, S. T., \& Wulff, S. (2005). Do foreign language learners also have constructions? Evidence from priming, sorting, and corpora. Annual Review of Cognitive Linguistics, 3, 182-200.

Gropen, J., Pinker, S., Hollander, M., Goldberg, R., \& Wilson, R. (1989). The learnability and acquisition of the dative alternation in English. Language, 65, 203-257.

Hartsuiker, R. J., \& Kolk, H. H. J. (1998). Syntactic persistence in Dutch. Language and Speech, 41, 143-184.

Hartsuiker, R. J., Bernolet, S., Schoonbaert, S., Speybroeck, S., \& Vanderelst, D. (2008). Syntactic priming persists while the lexical boost decays: Evidence from written and spoken dialogue. Journal of Memory and Language, 58, 214-238. http://dx.doi.org/10.1016/j.jml.2007.07.003

Hartsuiker, R. J., Pickering, M. J., \& Veltkamp, E. (2004). Is syntax separate or shared between languages? Cross-linguistic syntactic priming in Spanish-English bilinguals. Psychological Science, 15, 409-414.

Huang, S. (1994). A Comparative study of the dative alternation in Mandarin and Taiwanese. Unpublished manuscript, University of Hawai'i at Manoa.

Inagaki, S. (1997). Japanese and Chinese learners' acquisition of the narrow-range rules for the dative alternation in English. Language Learning, 47, 637-669. http://dx.doi.org/10.1111/0023-8333.00024

Jackendoff, R. (1990). Semantic structures. Cambridge, MA: MIT Press.

Jiang, L. (2009). Semantic priming in the priming of English dative constructions. Modern Foreign Languages, 1 , 59-67.

Langacker, R. W. (1991). Foundations of cognitive grammar Vol. II: Descriptive application. Stanford: Stanford University Press.

Langacker, R. W. (1987). Foundations of cognitive grammar: Vol. 1: Theoretical prerequisites. Stanford, CA: Stanford University Press.

Larson, R. (1988). On the double object construction. Linguistic Inquiry, 19, 335-391.

Mazurkewich, I., \& White, L. (1984). The acquisition of the dative alternation: Unlearning overgeneralizations. Cognition, 16, 261-283. http://dx.doi.org/10.1016/0010-0277(84)90030-1

McDonough, K. (2006). Interaction and syntactic priming: English L2 speakers' production of dative constructions. Studies in Second Language Acquisition, 28, 179-207. http://dx.doi.org/10.1017/S0272263106060098

McDonough, K., \& Mackey, A. (2008). Syntactic priming and ESL question development. Studies in Second Language Acquisition, 30, 31-47. http://dx.doi.org/10.1017/S0272263108080029

Pickering, M. J., \& Branigan, H. P. (1998). The representation of verbs: Evidence from syntactic priming in language production. Journal of Memory and Language, 39, 733-751. http://dx.doi.org/10.1006/jmla.1998.2592

Pinker, S. (1989). Learnability and cognition: The acquisition of argument structure. Cambridge, MA: MIT Press.

Scheepers, C. (2003). Syntactic priming of relative clause attachments: Persistence of structural configuration in sentence production. Cognition, 89, 179-205. http://dx.doi.org/10.1016/S0010-0277(03)00119-7

Schoonbaert, S., Hartsuiker, R. J., \& Pickering, M. J. (2007). The representation of lexical and syntactic information in bilinguals: Evidence from syntactic priming. Journal of Memory and Language, 56, 153-171. http://dx.doi.org/10.1016/j.jml.2006.10.002

Shin, J.-A. (2008). Structural priming in bilingual language processing and second language learning. Unpublished doctoral dissertation, University of Illinois at Urbana-Champaign.

Shin, J.-A. (2010). Structural priming and L2 proficiency effects on bilingual syntactic processing in production. Korean Journal of English Language and Linguistics, 10, 499-518.

Shin, J.-A., \& Christianson, K. (2012). Structural priming and second language learning. Language Learning, 62, 931-964. http://dx.doi.org/10.1111/j.1467-9922.2011.00657.x

Tomasello, M. (2003). Constructing a language. Cambridge, MA: Harvard University Press. 
Wang, C.-M. (2009). A study of the interrelationship between L2 learning variables and L2 use. Foreign Languages in China, 6, 53-59.

\section{Copyrights}

Copyright for this article is retained by the author(s), with first publication rights granted to the journal.

This is an open-access article distributed under the terms and conditions of the Creative Commons Attribution license (http://creativecommons.org/licenses/by/3.0/). 